Original Article - Clinical Science

\title{
Victorian trabeculectomy audit
}

J ennifer C Fan Gaskin FRANZCO MD, ${ }^{1,2}$ Sukhpal S Sandhu FRANZCO MD ${ }^{1,2}$ and Mark J Walland FRANZCO ${ }^{1,2}$

${ }^{1}$ Centre for Eye Research Australia, Melbourne, Victoria, Australia

${ }^{2}$ The Royal Victorian Eye and Ear Hospital, Melbourne, Victoria, Australia

Correspondence: Dr. J ennifer Fan Gaskin, Centre for Eye Research Australia, 32

Gisborne St, East Melbourne, VIC 3002, Australia

E-mail: drjfan@gmail.com

Short running title: Victorian trabeculectomy audit

Received 31 August 2016; accepted 9 March 2017

Conflict of interest: None

Funding sources: None

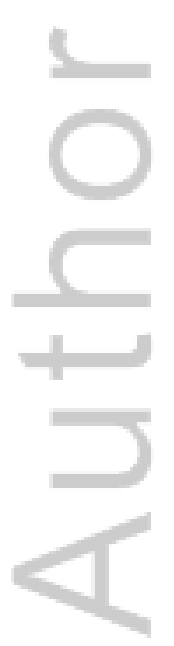

This is the author manuscript accepted for publication and has undergone full peer review but has not been through the copyediting, typesetting, pagination and proofreading process, which may lead to differences between this version and the Version of Record. Please cite this article as doi: 10.1111/ceo.12948

This article is protected by copyright. All rights reserved. 


\section{ABSTRACT}

I mportance: This study highlights the efficacy and safety of trabeculectomy in Victoria, Australia.

Background: Trabeculectomy is currently the gold- standard in glaucoma surgery. However, its role has been increasingly questioned due to its associated risks and complications. This audit aimed to assess the efficacy and safety of trabeculectomy surgery in the state of Victoria, Australia.

Design: A cross-sectional, retrospective, and voluntary state- wide audit of trabeculectomy surgery by individual surgeons in 2012 with 24-months follow-up. Participants: Twenty-four surgeons in the state of Victoria submitted data on 227 trabeculectomies.

Methods: Basic pre- and peri- operative data were collected. Post- operative data collected included intra-ocular pressure (IOP) measurements, glaucoma medications, associated complications and subsequent surgery up to 24-months posttrabeculectomy.

Main Outcome Measures: Post- operative IOP and surgical complications.

Results: At 12-months, the mean IOP was $12.6 \pm 4.1 \mathrm{mmHg}$ (range 3-28 mmHg). A total of $91 \%$ of eyes had an IOP $\leq 18 \mathrm{mmHg}$ with or without ocular hypotensive medications. One- third of eyes that were phakic at the time of trabeculectomy underwent cataract extraction within the 24-months of follow-up. Eyes that underwent combined cataract extraction and trabeculectomy (23\% of trabeculectomies) had a significantly higher mean 12-month IOP than eyes that 
underwent trabeculectomy alone (13.9 $\mathrm{mmHg}$ versus $12.2 \mathrm{mmHg}, \mathrm{p}=0.01)$. At 24months, there were no cases of blebitis/endophthalmitis.

Conclusions and Relevance: The Victorian Trabeculectomy Audit demonstrates excellent efficacy and safety results that are comparable to international standards. Combined cataract extraction and trabeculectomy tended to result in a higher mean post-operative IOP than trabeculectomy alone.

Key words: Glaucoma, trabeculectomy, filtration surgery, wound healing, antimetabolite, anti-fibrotic

\section{NTRODUCTION}

Trabeculectomy was introduced by Cairns in $1968^{1}$ and remains the most commonly performed procedure for the treatment of medically uncontrolled glaucoma.

Although technical aspects of the procedure have evolved over time, the underlying concept of the operation has changed little since Cairns' original description. It is still regarded as the gold-standard glaucoma operation.

Reduction of subconjunctival scarring and improvement in long-term safety have been the main motivations behind the evolution in trabeculectomy. Wound-healing modulation through the use of antimetabolites such as 5-fluorouracil (5-FU) and Mitomycin C (MMC) has seen an increase in long-term bleb survival due to a reduction in subconjunctival scarring. ${ }^{2-5}$ However, the introduction of antimetabolites has also been associated with significant sight-threatening complications, such as hypotony, ${ }^{6,7}$ late bleb leak, ${ }^{8}$ and endophthalmitis. ${ }^{9,10}$ Alterations in the surgical technique have been developed - such as addressing antimetabolite concentration, ${ }^{11}$ treatment area and application time; ${ }^{12}$ irrigation of the surgical site after antimetabolite application; ${ }^{13}$ conjunctival management and closure; ${ }^{14}$ and aqueous 
flow regulation with the placement of adjustable and releasable trans-scleral sutures $^{14}$ - to diminish the rates of these sight-threatening complications.

Published data of improved outcomes as a result of these technique modifications have largely come from single surgeons and/or centres. ${ }^{2,5,15,16}$ There has only been one associated study from Australasia on the subject, in the form of a postal questionnaire focused primarily on the use of antimetabolites in trabeculectomies. ${ }^{17}$ Recently Kirwan et al ${ }^{18}$ published a cross-sectional survey of trabeculectomy outcomes from nine glaucoma units in the United Kingdom (UK), which demonstrated that $87 \%$ of 428 eyes achieved IOP of $\leq 21 \mathrm{mmHg}$ at 2 years with or without ocular hypotensive medications. The bleb-related endophthalmitis rate was $0.5 \%$ and no patient lost perception of light. This study has established the new benchmark for trabeculectomy outcomes in the UK.

To achieve a better understanding of both the nature of trabeculectomies performed in our own region and also their outcomes in comparison to other published data particularly the study by Kirwan et $a_{1}{ }^{18}$ - we conducted a cross-sectional, state-wide audit of the current performance of primary trabeculectomies in Victoria, Australia.

\section{METHODS}

All Victorian ophthalmologists who were registered fellows of the Royal Australian and New Zealand College of Ophthalmologists (RANZCO) were invited by email to conduct a personal audit of primary trabeculectomies performed in their private practice for a calendar year. Primary trabeculectomy was defined as the first intraoperative glaucoma operation performed on the eye (excluding isolated lens surgery for a glaucoma indication). Previous selective laser trabeculoplasty or other outpatient laser procedures were permitted, but eyes with prior cyclodiode laser 
therapy were excluded. The year 2012 was selected to allow for a 2-year follow-up period. An Excel spreadsheet (Microsoft Corp, Redmont, WA) with labeled columns of the required information was attached to the email. Each patient was coded within the spreadsheets for confidentiality.

Pre- and peri-operative data requested included: number of trabeculectomies performed by the surgeon over the 12-months, patient risk factors for failure (including age $<30$ years, history of uveitis, secondary glaucoma or cicatrizing disease, and previous conjunctival surgery), adjunctive antimetabolite usage and type, and whether concurrent cataract extraction was performed.

Post-operative data requested included: IOP at 12-months, number of eyes with IOP $<18 \mathrm{mmHg}$ with or without ocular hypotensive medications, number of postoperative antimetabolite injections, number of subsequent bleb needlings with or without antimetabolite, incidence of early or late blebitis, incidence of severe visual loss following trabeculectomy, and whether subsequent cataract surgery was performed. Severe visual loss was defined as a reduction in visual acuity to light perception (PL) or no light perception (NPL).

Participating ophthalmologists returned the completed spreadsheets and the data were collated and analysed with the assistance of a bio-statistician. These persurgeon summaries were pooled using meta-analytic methods. Pooled estimates were calculated separately for two study groups: surgeons with more than 10 surgeries and those surgeons with 10 or fewer surgeries. For intraoperative use of MMC, the Stata command 'metaprop' used the Freeman-Tukey Double Arcsine Transformation ${ }^{19}$ to stabilize the variances for the per-surgeon proportions, and the random effects method to calculate pooled estimates of proportion and $95 \%$ confidence intervals based on score (Wilson) ${ }^{20}$ For 12 -month IOP, the command 
'metan' used the per-surgeon mean and standard error, and the DerSimonian \& Laird random effects method to calculate pooled estimates of mean and $95 \%$ confidence interval. Estimates of heterogeneity were taken from the inversevariance fixed-effect model. Forest plots were produced sorted by number of surgeries performed and stratified by study groups.

All tests were two-tailed and p-values are quoted where appropriate. Ethics approval was obtained from the Royal Victorian Eye and Ear Hospital (RVEEH) Human Research and Ethics Committee.

\section{RESULTS}

Three hundred and eighty-nine primary trabeculectomies were performed in 2012 in Victoria according to Medicare's database (Medicare Benefit Schedule (MBS) code 42746), which annotates private practice activity. Twenty-four surgeons participated in the audit and submitted data on all the trabeculectomies they performed privately in 2012. Collectively they performed 227 trabeculectomies, accounting for $58 \%$ of the total number of Victorian private practice trabeculectomies in 2012. The number of trabeculectomies performed per surgeon ranged from 1 to 56 , with 5 of the 24 surgeons (21\%) being responsible for 141 cases (62.1\%), and 16 surgeons (67\%) performing fewer than 10 trabeculectomies that year (see table 1).

Two hundred and twenty of the 227 cases (97\%) underwent trabeculectomy with adjunctive antimetabolite, with MMC accounting for 185 cases (81.5\%) and 5-FU the remainder. No other anti-scarring agent was used in any of the cases. All forty-eight eyes $(21.1 \%)$ that had one or more risk factors for failure underwent trabeculectomy with an antimetabolite; 47 with MMC, and one with 5-FU. 
Post-operatively, 91 eyes (41.4\%) received 5-FU injections without bleb needling; the range of 5-FU injections was 1-9 injections per eye across the 24-month followup period. Thirty-two cases (14.1\%) underwent bleb needling post-operatively, 4 of which were performed without an adjunctive antimetabolite, with a range of 1-6 needlings/eye (total number of needlings $=59$ ). Antimetabolite use, both intra- and post-operatively has been displayed in figure 1 .

Fifty of the 227 trabeculectomies (22\%) in this audit were performed in conjunction with phacoemulsification cataract surgery. Ninty-four (41\%) eyes were pseudophakic at the time of trabeculectomy, and a further $28(12 \%)$ went on to undergo cataract extraction during the 24-month follow-up period; this represented $34 \%$ of the patients who were phakic following trabeculectomy.

At 12 -months, the mean IOP was $12.6 \pm 4.1 \mathrm{mmHg}$ (range $3-28 \mathrm{mmHg}$ ): 178 cases (78.4\%) had an IOP of $\leq 18 \mathrm{mmHg}$ without any ocular hypotensive medications (complete success); a further 29 (13\%) eyes achieving IOP $\leq 18 \mathrm{mmHg}$ with ocular hypotensive medication (qualified success). A total of 218 eyes achieved $<21 \mathrm{mmHg}$ with or without ocular hypotensive medications (96\%). There was no statistically significant difference in 12-month IOP when comparing whether the surgeon performed $<10$ or $\geq 10$ trabeculectomies that year, whether antimetabolites were used, or the type of antimetabolite used. However, eyes that underwent combined cataract extraction and trabeculectomy had a significantly higher mean 12-month IOP than eyes that underwent trabeculectomy alone (13.9 mmHg versus 12.2 $\mathrm{mmHg}, \mathrm{p}=0.01$ ) (figure 2). Table 2 outlines the management and outcome differences between eyes that underwent trabeculectomy alone versus combined cataract extraction and trabeculectomy. 
At 24-months, there were no cases of early or late blebitis/endophthalmitis. However, 3 of the 227 cases (1.3\%) sustained severe visual loss following filtration surgery.

\section{DISCUSSION}

Glaucoma surgery is currently undergoing a considerable 'facelift' with the introduction of minimally invasive glaucoma surgery (MIGS). The advent of MIGS is due in part to the potentially devastating complications associated with conventional glaucoma operations. Whilst it is widely recognised that MIGS is unlikely to achieve the level of IOP reduction that a trabeculectomy can achieve - but may rather decrease topical medication dependency ${ }^{21}$ - it does invite a reappraisal of the role of glaucoma filtration surgery in the $21^{\text {st }}$ century.

This study demonstrates that trabeculectomy is still a successful operation in the treatment of glaucoma, based on IOP outcomes. Approximately $80 \%$ of cases achieve $\leq 18 \mathrm{mmHg}$ without ocular hypotensive medications at 12-months, and $90 \%$ achieve this if ocular hypotensive medications are added; a total of 218 eyes achieved $<21 \mathrm{mmHg}$ with or without ocular hypotensive medications (96\%). This is comparable to a UK study by Kirwan et al, which demonstrated that $78 \%$ achieved complete success and $86 \%$ achieved qualified success at 2 years. ${ }^{18}$ There were also no cases of blebitis or endophthalmitis reported in the 2-year follow up period in this cohort, which is therefore comparable to the rate reported by Kirwan et al $(0.23 \%)^{18}$

Compared to a report on previous practices in Australia (Liu et al.) and other studies, Victorian surgeons are now more likely to use MMC as an adjunctive antimetabolite than other agents, with MMC utilized in $85 \%$ of cases, compared to $63 \%$ in the 
study by Kirwan et al., ${ }^{18}$ and only $12 \%$ in the study by Liu et al. which dates from 2008 and presumably reflects practice shortly prior to that. ${ }^{17}$ This study also demonstrated a higher frequency of postoperative antimetabolite injections without needling compared to the British study ( $41 \%$ vs. $28 \%) .{ }^{18}$

Twenty-three percent of the trabeculectomies performed in this study were combined with cataract surgery. Combined cases were excluded from the UK study by Kirwan et al. and therefore the frequency with which they are performed is not known. However, combined surgery is the one factor that affected the 12-month IOP in our analysis. Indeed, if the combined cases were removed from the analysis, even better results were demonstrated with $99 \%$ achieving $<18 \mathrm{mmHg}$ with or without ocular hypotensive medication. A significantly higher proportion of cases were pseudophakic by the time they required trabeculectomy in our cohort compared to the cohort of Kirwan et al (43\% vs. $13 \%$ ). A further $13 \%$ of eyes in our cohort went on to require cataract surgery in the 2-year follow-up period; this represents $34 \%$ of eyes that remained phakic following glaucoma filtration surgery. Interestingly, Kirwan et al. reported a very similar number of eyes requiring cataract surgery in the 24-months subsequent to trabeculectomy (31\%).

The ideal timing of cataract surgery in relation to glaucoma surgery is debated. It is recognised that cataract surgery negatively affects the function of an existing bleb, especially with less time elapsed between trabeculectomy and cataract surgery. ${ }^{22}$ On the other hand, trabeculectomy within 6 months of cataract surgery may be associated with a higher rate of failure. ${ }^{23}$ Finally, combined surgery has been reported to have a lower success rate and higher rate of bleb failure compared to trabeculectomy alone, ${ }^{24,25}$ and this is consistent with our findings. We can only speculate whether the comparatively higher rate of pseudophakic patients at the time of trabeculectomy in Victoria - as compared to the UK - represents efforts by 
local surgeons to 'clear the ground' in preparation for trabeculectomy, or may instead reflect the Australian private practice population versus the UK NHS population, particularly in relation to rates of lens extraction.

The role of the general ophthalmologist in the performance of trabeculectomy is an ongoing discussion: the number of trabeculectomies performed has decreased with the development of more effective medications and laser therapy. ${ }^{26}$ Compared to the study by Liu et al. ${ }^{17}$ reporting that $75 \%$ of respondents across Australia and New Zealand performed less than 10 trabeculectomies/year, the number of surgeons performing less than 10 trabeculectomies in a year has reduced to $67 \%$ in our study. Certainly in the study by Kirwan et al., ${ }^{18}$ only glaucoma units led by fellowshiptrained glaucoma specialists were surveyed for the purpose of establishing a benchmark. Many would argue that less than 10 cases per year is suboptimal for maintaining surgical excellence for a sub-specialised procedure. We compared the outcomes of cases performed by surgeons who conducted $<10$ trabeculectomies with those who conducted $\geq 10$ trabeculectomies in 2012, however, and identified no significant differences in 12-month IOP or complication rates, which is an encouraging result when bench-marked against the sub-specialist-led UK study results. The updated curriculum guidelines of RANZCO retain trabeculectomy as a core learning skill for an ophthalmology trainee. ${ }^{27}$

This study has several limitations, foremost of which is the obvious responder selection bias. As a voluntary, surgeon-conducted audit, it is conceivable that more surgeons may have conducted the audit on their own patient cohort but then declined to submit their data due to undesirable outcomes discovered, even given that data were de-identified. Therefore our results may not reflect accurately the true Victorian trabeculectomy outcomes. Secondly, many other factors could have influenced the trabeculectomy outcomes, such as type of glaucoma, indication for 
surgery, pre-operative IOP, length of pre-operative glaucoma medication usage, and specific surgical technique. However, to maximise the ease of data collection and submission, we elected to request core information only. Finally, we are guarded in our comparison of outcomes to the UK study - and others that were conducted on public hospital patients -

as our cohort was managed entirely in the private sector, therefore excluding the involvement of trainee surgeons and other potential differences such as restrictions in follow-up appointments in public sector clinics. An audit of the outcomes of the trabeculectomies performed in the Victorian public hospital system would be of much interest for future study as a direct comparison to this study and also to the study by Kirwan et al.

The Victorian trabeculectomy audit has demonstrated excellent IOP and safety outcomes that are comparable to the best-reported international standards. It has identified a trend to more MMC usage in the choice of adjunctive antimetabolite in trabeculectomy. Trabeculectomy combined with cataract surgery tends to result in a higher mean post-operative IOP than trabeculectomy alone. However, just over onethird of phakic patients required cataract extraction in the 24-months following trabeculectomy. Surgical volume does not appear to be correlated with IOP outcomes from trabeculectomy. Based on our findings, trabeculectomy remains a realistic surgical option for the treatment of glaucoma in Australia.

\section{Acknowledgements}

The authors would like to acknowledge the input of Nicholas Brislane and Sophie Rogers, biostatistician, for their assistance in the data collection and analysis of this study. 


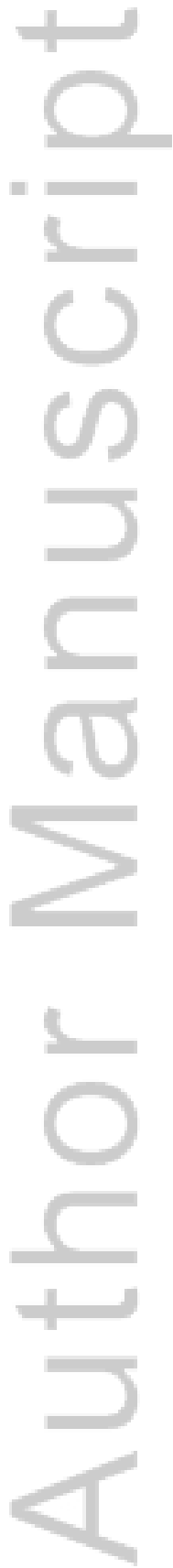

This article is protected by copyright. All rights reserved. 


\section{REFERENCES}

1. Cairns JE. Trabeculectomy. Preliminary report of a new method. American journal of ophthalmology. 1968;66(4):673-679.

2. Reibaldi A, Uva MG, Longo A. Nine-year follow-up of trabeculectomy with or without low-dosage mitomycin-c in primary open-angle glaucoma. The British journal of ophthalmology. 2008;92(12):1666-1670.

3. = Beckers HJ, Kinders KC, Webers CA. Five-year results of trabeculectomy with mitomycin C. Graefe's archive for clinical and experimental ophthalmology = Albrecht von Graefes Archiv fur klinische und experimentelle Ophthalmologie. 2003;241(2): 106-110.

4. Fontana H, Nouri-Mahdavi K, Lumba J, Ralli M, Caprioli J. Trabeculectomy with mitomycin C: outcomes and risk factors for failure in phakic open-angle glaucoma. Ophthalmology. 2006; 113(6):930-936.

5. Five-year follow-up of the Fluorouracil Filtering Surgery Study. The Fluorouracil Filtering Surgery Study Group. American journal of ophthalmology. 1996; 121(4):349-366.

6. Kupin TH, J uzych MS, Shin DH, Khatana AK, Olivier MM. Adjunctive mitomycin $\mathrm{C}$ in primary trabeculectomy in phakic eyes. American journal of ophthalmology. 1995; 119(1):30-39.

7. Zacharia PT, Deppermann SR, Schuman JS. Ocular hypotony after trabeculectomy with mitomycin C. American journal of ophthalmology. 1993;116(3):314-326.

8. Greenfield DS, Liebmann J M, J ee J, Ritch R. Late-onset bleb leaks after glaucoma filtering surgery. Archives of ophthalmology. 1998;116(4):443-447.

9. Katz LJ, Cantor LB, Spaeth GL. Complications of surgery in glaucoma. Early and late bacterial endophthalmitis following glaucoma filtering surgery. Ophthalmology. 1985; 92(7):959-963. 
10. Greenfield DS, Suner IJ, Miller MP, Kangas TA, Palmberg PF, Flynn HW, J r. Endophthalmitis after filtering surgery with mitomycin. Archives of ophthalmology. 1996; 114(8):943-949.

11. Vass C, Georgopoulos M, el Menyawi I, Radda S, Nimmerrichter P. Intrascleral concentration vs depth profile of mitomycin- $\mathrm{C}$ after episcleral application: impact of applied concentration and volume of mitomycin-C solution. Experimental eye research. 2000;70(5):571-575.

12. = Robin AL, Ramakrishnan R, Krishnadas R, et al. A long-term dose-response study of mitomycin in glaucoma filtration surgery. Archives of ophthalmology. 1997;115(8):969-974.

13. Vass C, Georgopoulos M, El Menyawi I, Radda S, Nimmerrichter P, Menapace R. Intrascleral concentration vs depth profile of mitomycin-C after episcleral application: impact of irrigation. Experimental eye research. 2000;70(2):139143.

14. Dhingra S, Khaw PT. The moorfields safer surgery system. Middle East African journal of ophthalmology. 2009;16(3):112-115.

15. Membrey WL, Poinoosawmy DP, Bunce $C$, Hitchings RA. Glaucoma surgery with or without adjunctive antiproliferatives in normal tension glaucoma: 1 intraocular pressure control and complications. The British journal of ophthalmology. 2000;84(6):586-590.

16. Megevand GS, Salmon JF, Scholtz RP, Murray AD. The effect of reducing the exposure time of mitomycin C in glaucoma filtering surgery. Ophthalmology. 1995; 102(1):84-90.

17. Liu L, Siriwardena D, Khaw PT. Australia and New Zealand survey of antimetabolite and steroid use in trabeculectomy surgery. Journal of glaucoma. 2008;17(6):423-430.

18. Kirwan JF, Lockwood AJ, Shah P, et al. Trabeculectomy in the 21st century: a multicenter analysis. Ophthalmology. 2013;120(12):2532-2539. 
19. Freeman MF TJ. Transformations related to the angular and the square root. . Annals of Mathematical Statistics. 1950;21:607-611.

20. Newcombe RG. Two-sided confidence intervals for the single proportion: comparison of seven methods. Stat Med. 1998;17(8):857-872.

21. Richter GM, Coleman AL. Minimally invasive glaucoma surgery: current status and future prospects. Clinical ophthalmology. 2016;10:189-206.

22. Husain R, Liang S, Foster PJ, et al. Cataract surgery after trabeculectomy: the effect on trabeculectomy function. Archives of ophthalmology. 2012;130(2): 165-170.

23. Siriwardena D, Kotecha A, Minassian D, Dart JK, Khaw PT. Anterior chamber flare after trabeculectomy and after phacoemulsification. The British journal of ophthalmology. 2000;84(9):1056-1057.

24. Chang L, Thiagarajan M, Moseley M, et al. Intraocular pressure outcome in primary 5FU phacotrabeculectomies compared with 5FU trabeculectomies. Journal of glaucoma. 2006;15(6):475-481.

25. Lochhead J, Casson RJ, Salmon J F. Long term effect on intraocular pressure of phacotrabeculectomy compared to trabeculectomy. The British journal of ophthalmology. 2003;87(7):850-852.

26. Kerr NM, Kumar HK, Crowston JG, Walland MJ . Glaucoma laser and surgical procedure rates in Australia. The British journal of ophthalmology. 2016.

27. https://ranzco.edu/ArticleDocuments/187/STANDARD Glaucoma.pdf.aspx?Embed=Y. 


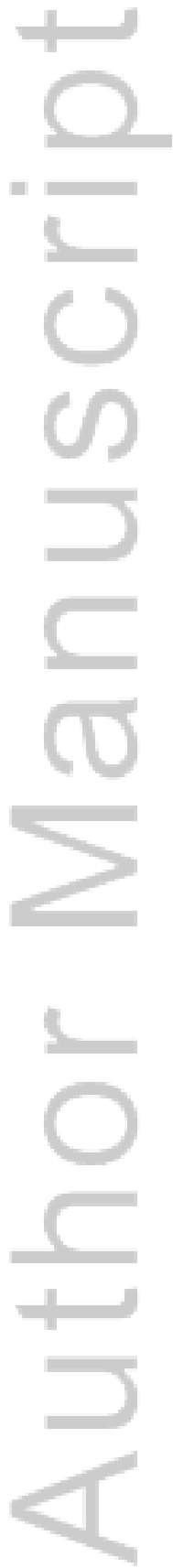

This article is protected by copyright. All rights reserved. 
TABLES

Table 1: Surgeon data

Number ( $\mathrm{n})$

227

Total number of surgeons

24

Range of trabeculectomies performed per surgeon in 2014

$1-56$

\begin{tabular}{|l|l}
\hline Number of surgeons who performed $<10$ trabeculectomies in 2014 & 16
\end{tabular}

This article is protected by copyright. All rights reserved. 
Table 2: Comparison of management and outcome details between trabeculectomy only with combined cataract extraction and trabeculectomy.

\begin{tabular}{|l|c|c|}
\hline & $\begin{array}{c}\text { Trabeculectomy } \\
\text { only }\end{array}$ & $\begin{array}{c}\text { Combined phaco- } \\
\text { trabeculectomy }\end{array}$ \\
\hline Number $(\mathrm{n})$ & 177 & 50 \\
\hline $\begin{array}{l}\text { Performed in conjunction with MMC } \\
(\%)\end{array}$ & $156(88)$ & $29(58)$ \\
\hline $\begin{array}{l}\text { Performed in conjunction with 5-FU } \\
(\%)\end{array}$ & $18(10)$ & $18(36)$ \\
\hline $\begin{array}{l}\text { Number of bleb needlings with } \\
\text { antimetabolite }\end{array}$ & 39 & 15 \\
\hline $\begin{array}{l}\text { Number of bleb needlings without } \\
\text { antimetabolite }\end{array}$ & 5 & 47 \\
\hline $\begin{array}{l}\text { Number of antimetabolite injections } \\
\text { without needling }\end{array}$ & 199 & $13.9 \pm 3.19$ \\
\hline IOP at 12-months \pm SD & $136(77)$ & $42(84)$ \\
\hline $\begin{array}{l}\text { Number achieved <18 mmHg } \\
\text { without ocular hypotensive } \\
\text { medications (\%) }\end{array}$ & $2(1)$ & $46(98)$ \\
\hline $\begin{array}{l}\text { Number achieved <18 mmHg with } \\
\text { or without ocular hypotensive } \\
\text { medications (\%) }\end{array}$ & 1 (2) \\
\hline $\begin{array}{l}\text { Severe visual loss following surgery } \\
\text { (\%) }\end{array}$ & & 4.29 \\
\hline
\end{tabular}

$\mathrm{MMC}=$ Mitomycin C; 5-FU = 5-fluorouracil; IOP = Intraocular pressure; SD = Standard deviation 


\section{FIGURES}

Figure 1: The intraoperative and postoperative application of antimetabolites

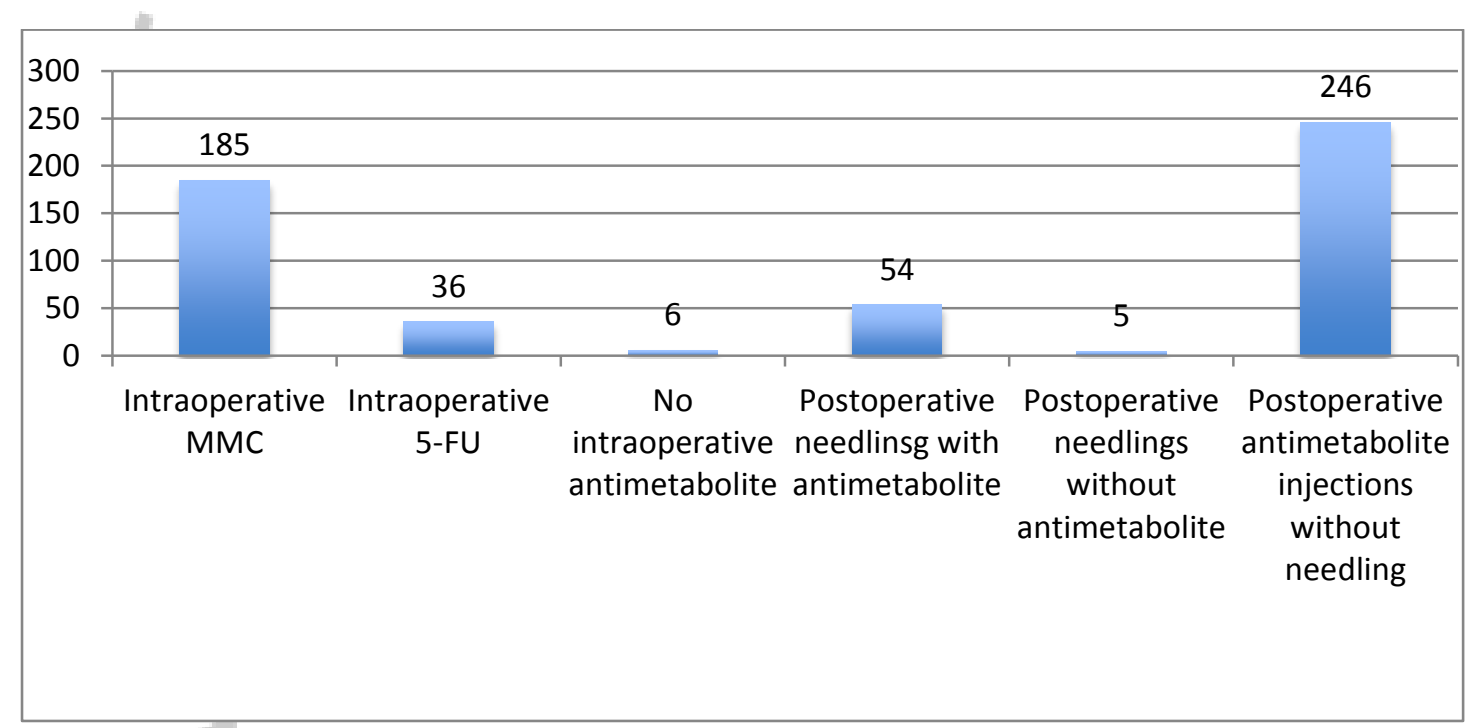

$M M C=$ Mitomycin C; 5-FU = 5-fluorouracil

This article is protected by copyright. All rights reserved. 
Figure 2: Comparison of outcome in intraocular pressure between eyes that received trabeculectomy alone versus trabeculectomy with cataract surgery

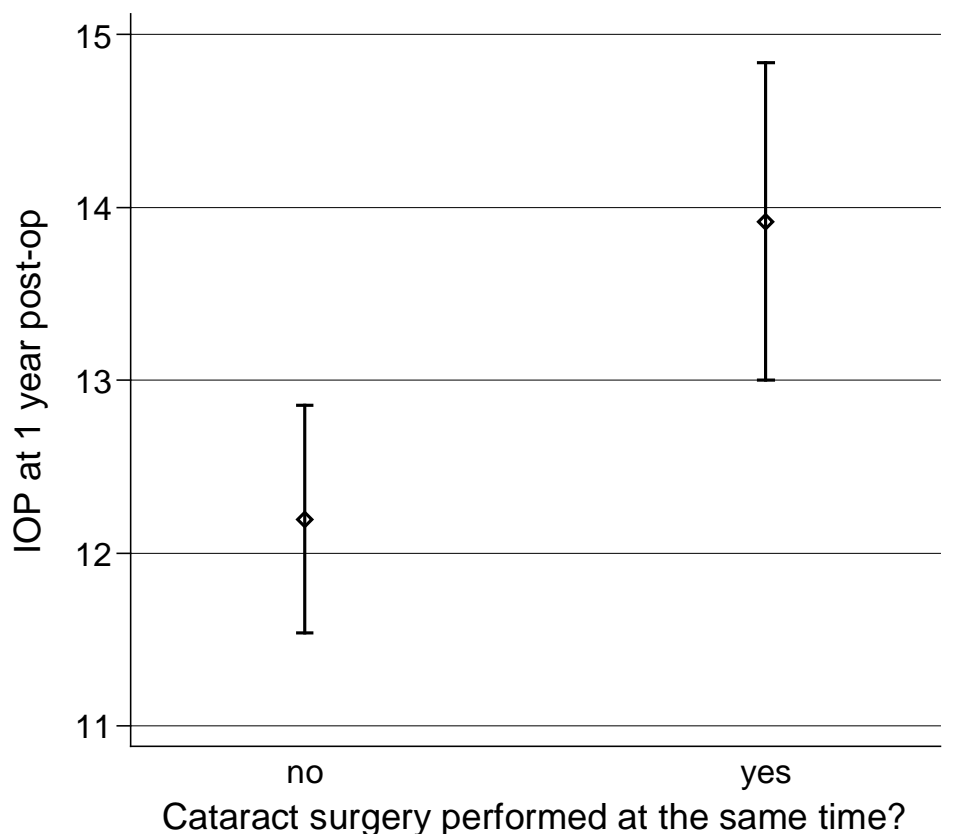

Cataract surgery performed at the same time?

$95 \%$ confidence intervals

$\mathrm{IOP}=$ intraocular pressure

This article is protected by copyright. All rights reserved. 


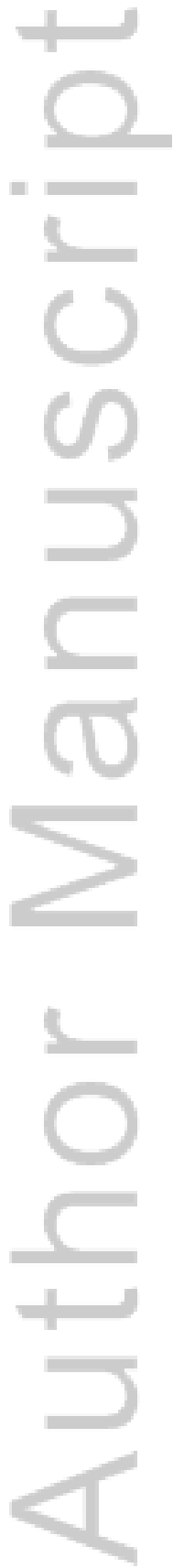

This article is protected by copyright. All rights reserved. 


\section{University Library}

\section{- M M I E E R VA A gateway to Melbourne's research publications}

Minerva Access is the Institutional Repository of The University of Melbourne

Author/s:

Gaskin, JCF;Sandhu, SS;Walland, MJ

Title:

Victorian trabeculectomy audit

Date:

2017-09-01

Citation:

Gaskin, J. C. F., Sandhu, S. S. \& Walland, M. J. (2017). Victorian trabeculectomy audit. CLINICAL AND EXPERIMENTAL OPHTHALMOLOGY, 45 (7), pp.695-700. https:// doi.org/10.1111/ceo.12948.

Persistent Link:

http://hdl.handle.net/11343/292814 